\title{
Intrasellar Schwannoma Mimicking Pituitary Adenoma
}

\section{: A Case Report}

\begin{abstract}
Intrasellar location of schwannoma is extremely rare, although intracranial schwannomas account for up to $8 \%$ of all primary brain tumors. An unusual case of an intrasellar schwannoma radiographically and clinically simulating a pituitary adenoma is reported. A 39-yr-old man presented a 10-month history of visual disturbance and decreased libido. Neurological examination showed poor visual acuity of both eyes with bitemporal hemianopsia. Computed tomography and magnetic resonance imaging showed a sellar tumor with suprasellar extension. Pituitary adenoma was considered as a preoperative diagnosis. The tumor was removed through a trans-sphenoidal approach. Microscopic examination of the tumor revealed schwannoma.
\end{abstract}

Key Words : Schwannoma, Pituitary Neoplasms

\author{
Sung Mock Whee, Jung-II Lee, \\ Jong Hyun Kim \\ Department of Neurosurgery, Samsung Medical \\ Center, Sungkyunkwan University School of \\ Medicine, Seoul, Korea \\ Received : 9 February 2001 \\ Accepted : 20 April 2001 \\ Address for correspondence \\ Jong Hyun Kim, M.D. \\ Department of Neurosurgery, Samsung Medical \\ Center, Sungkyunkwan University School of \\ Medicine, 50 Ilwon-dong, Kangnam-gu, Seoul \\ 135-710, Korea \\ Tel : +82.2-3410-3499, Fax : +82.2-3410-0048 \\ E-mail : jonghkim@smc.samsung.co.kr
}

\section{INTRODUCTION}

Intracranial schwannomas are relatively common tumors comprising $8 \%$ of all primary intracranial neoplasms (1), and most frequently located in the cerebello-pontine angle originating from the vestibular component of the eighth cranial nerve. Intracranial schwannomas not related to cranial nerves are very rare and especially intrasellar location of schwannomas has been reported in only four publications (2-5). The authors present a primary intrasellar schwannoma that mimicked a pituitary tumor both clinically, and radiographically.

\section{CASE REPORT}

A 39-yr-old man visited the outpatient clinic due to decreased visual acuity of both eyes for 10 months. In addition, he complained of the loss of libido and impotence. Visual testing showed 20/60 and 20/160 acuity in each side. Visual field examination showed a bitemporal hemianopsia. Otherwise, no remarkable findings were found on the complete physical and neurological examinations. M agnetic resonance imaging (MRI) revealed enlarged sellar turcica and sellar mass with suprasellar extension (Fig. 1). The signal of the lesion was isointense to cerebral cortex in T1-weighted image, and slightly hyperintense in T2-weighted image. The mass was homogeneously enhanced after administration of gadolin- ium. Detailed preoperative endocrine testing revealed hypopituitarism. The patient showed el evated prolactin level $41.7 \mathrm{ng} / \mathrm{mL}$ (normal, less than $16.1 \mathrm{ng} / \mathrm{mL}$ ) and depressed GH $0.27 \mathrm{ng} / \mathrm{mL}$ (normal, $1-5 \mathrm{ng} / \mathrm{mL}$ ), LH $1.0 \mathrm{mlU} / \mathrm{mL}$ (normal, $1.4-11.1 \mathrm{mIU} / \mathrm{mL}$ ), FSH $1.0 \mathrm{mlU} / \mathrm{mL}$ (normal, $1.6-17.8 \mathrm{mlU} / \mathrm{mL}$ ), testosterone $0.03 \mathrm{ng} / \mathrm{mL}$ (normal, 2.79 $8.76 \mathrm{ng} / \mathrm{mL}$ ), and cortisol $0.6 \mu \mathrm{g} / \mathrm{mL}$ (normal, $5.9-26.1 \mu \mathrm{g} /$ $\mathrm{mL}$ ). A TRH stimulation test was performed giving a base line TSH of $1.94 \mu \mathrm{lU} / \mathrm{mL}$ to a peak TSH of $6.61 \mu \mathrm{lU} / \mathrm{mL}$ at $60 \mathrm{~min}$, which was consistent with a normal response.

Insulin tolerance test demonstrated an impaired response of plasma cortisol to lowered blood sugar with a peak of 1.6 $\mu \mathrm{g} / \mathrm{mL}$. The responses of LH and FSH values after LHRH stimulation were significantly depressed. The pre-operative diagnosis of pituitary adenoma was made. A trans-sphenoidal approach was selected for the removal of the sellar mass. We noticed a hypervascularized fibrous tumor with a harder consistency than that of usual pituitary adenomas. The tumor was removed incompletely because of its tight attachment to the optic nerves and chiasm. The final pathological diagnosis was schwannoma. Microscopic examination showed a spindle cell tumor consistent with schwannoma. Immunohistochemistry for S-100 protein was strongly positive, whereas that for glial fibrillary acidic protein (GFAP) was negative(Fig. 2).

Postoperative endocrinological test revealed panhypopituitarism basically similar to the preoperative state with a little aggravation. In addition, the patient experienced a tran- 

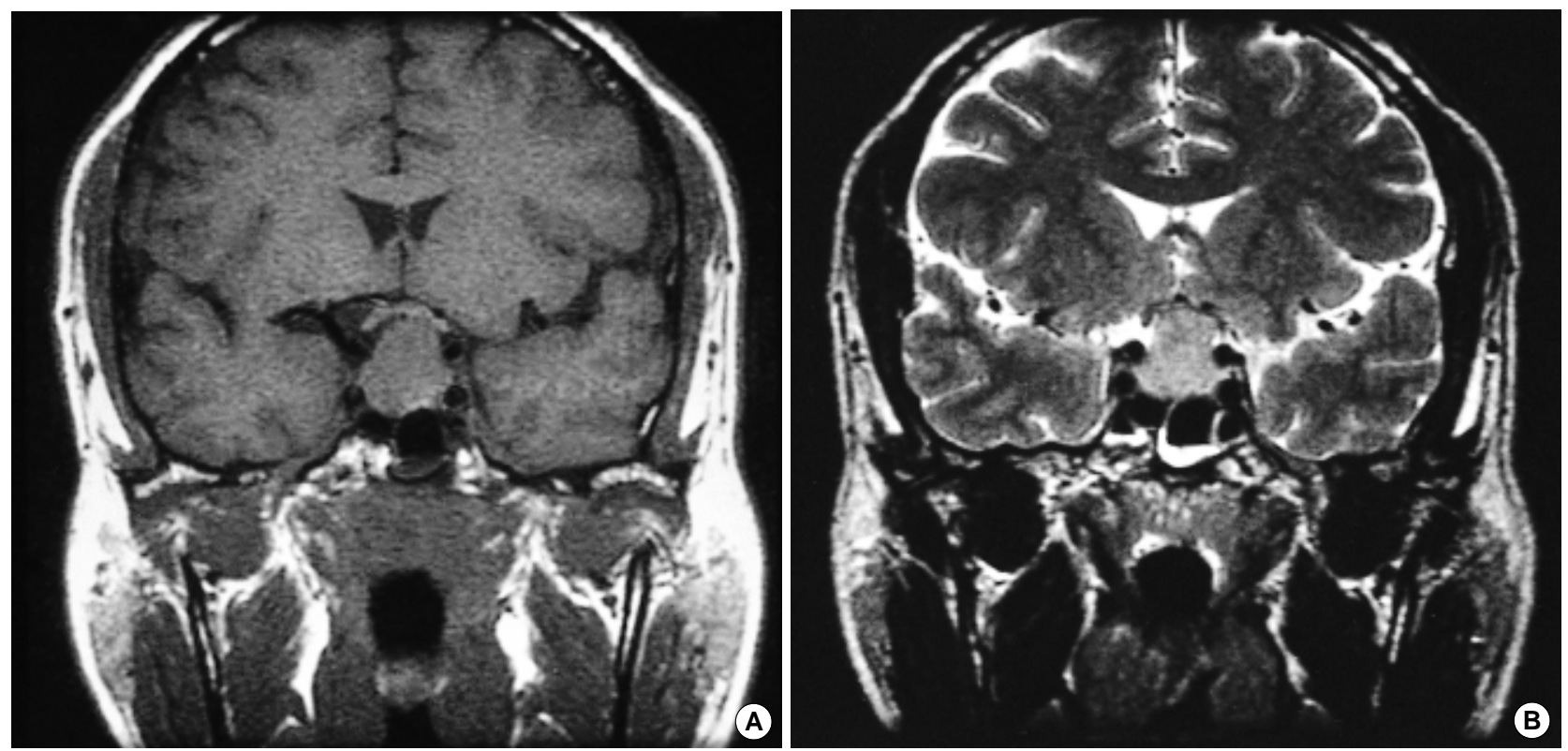

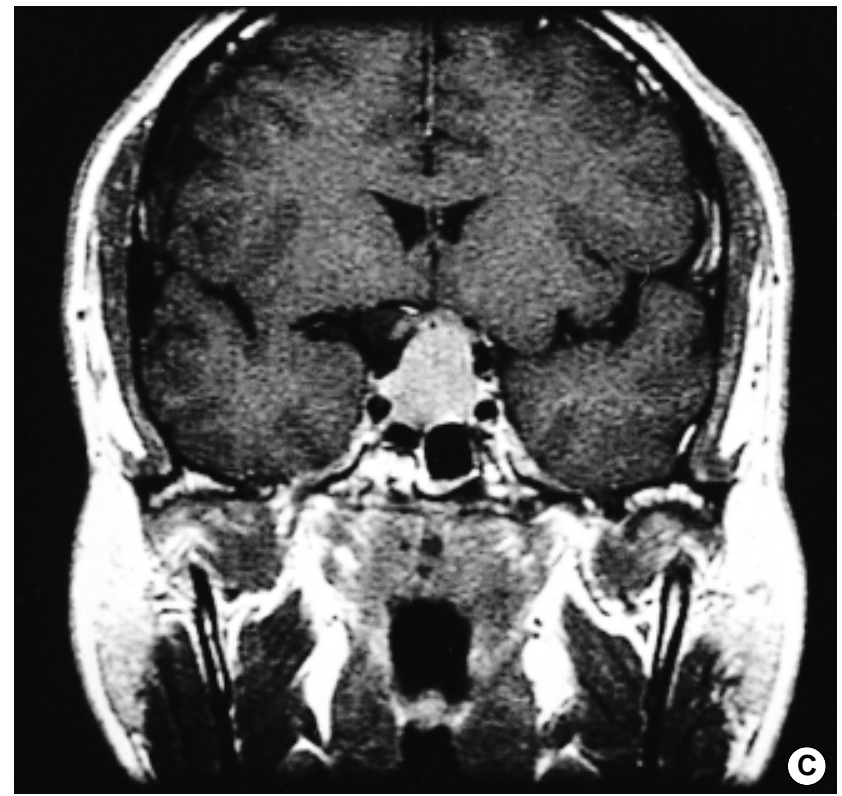

sient diabetes insi pidus. Postoperative visual testing showed a remarkable improvement in the visual field with an acuity of 20/25 in the right eye and 20/60 in the left eye. Thepatient underwent a replacement therapy of cortisol and thyroxine for 14 months following the surgery. A follow-up M RI scan 14 months after the operation showed no evidence of tumor regrowth.

\section{DISCUSSION}

The differential diagnoses of sellar and suprasellar lesions include pituitary adenomas, craniopharyngiomas, meningiomas, and many others. H owever, schwannoma is not usu-
Fig. 1. Coronal T1-weighted magnetic resonance image $(A)$ shows the lesion with isointense signal, and T2-weighted image (B) demonstrates the hyperintense signal. Gadolinium-enahnced coronal image $(\mathrm{C})$ shows a homogeneously enhanced intrasellar mass with suprasellar extension which is compressing the optic chiasm.

ally included, because the occurrence of schwannoma in the sellar or suprasellar region is exceedingly rare. Only four cases of intrasellar schwannomas have been reported previously, all of which presented a suprasellar extension similar to that of our case (2-5). Enlargement of the sella turcica and an enhancing sellar mass with suprasellar extension are most often associated with pituitary adenomas (6) and radiological findings in these cases were not significantly different from the usual pituitary macroadenomas. In T1-weighted MRI scan usually the schwannoma has an isointense or hypointense signal compared to brain cortex as like pituitary adenoma. The schwannoma in T2-weighted image shows more frequently hyperintense signal than pituitary adenoma. However, it is possible for pituitary adenoma to have 

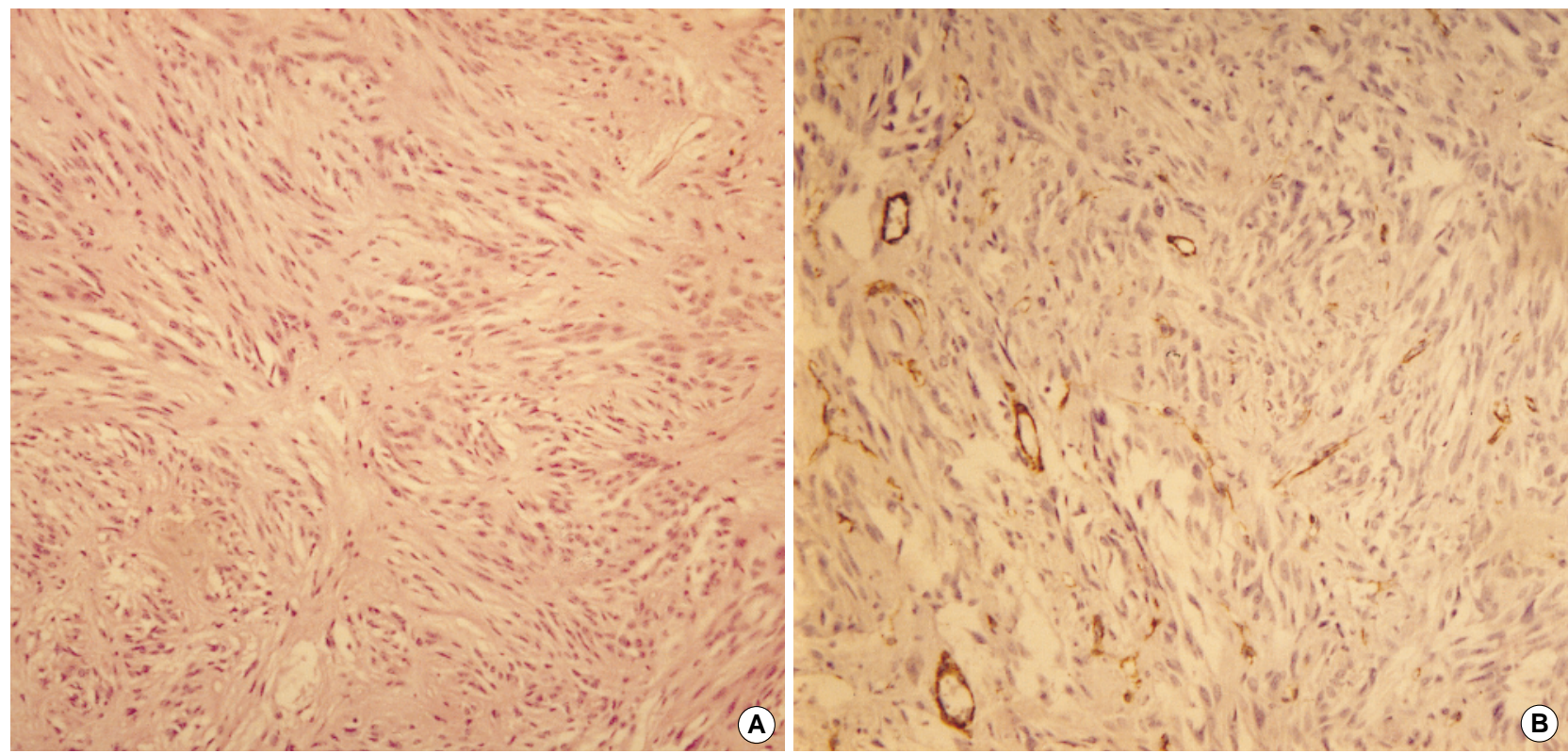

Fig. 2. (A) Photomicrogragh of pathologic specimen shows a typical pattern of schwannoma consisting of spindle cells $(\mathrm{H} \& \mathrm{E}, \times 100)$. (B) Immunohistochemical staining for S-100 protein is shown as positive $(\times 100)$.

variable findings including hyperintense signal which is not different from usual schwannomas. So MRI findings could not provide information favoring schwannoma even if the images were reviewed retrospectively. Clinically three out of four cases developed with visual change and two out of four showed pituitary insufficiency. Varying degrees of hypopituitarism have been found with the empty sella syndrome, intracranial aneurysms, pituitary adenomas, craniopharygiomas, chordomas, and meningiomas. So, the presence of pituitary insufficiency is not helpful for the differential diagnoses either, and the diagnosis is established by light microscopic examination of surgical specimens. Immunohistochemistry is of value to rule out other tumors such as fibroblastic meningioma, pilocytic astrocytoma, glioma, and metastatic tumors which may have palisading structures mimicking a schwannoma (7).

In our case the lesion was removed through the trans-sphe noidal approach as in the previous four reports (2-5). Surgical removal of these lesions by the trans-sphenoidal approach seems tougher than operation of pituitary adenoma due to the harder consistency and greater vascularity of schwannoma.

Total removal of the tumor was possible in only one of the previous cases. In theothers induding our case, the tumor could not be removed completely. Though none of the reported cases required a second operation for remnant tumors, additional treatment such as radiosurgery needs to be considered because the follow-up period in previous cases was too short to determine the prognosis.

The origin of intrasellar schwannoma is still being debated. Schwann cells are not normally found in the central ner- vous system. Three histopathological hypotheses have been previously discussed. Russell and R ubinstein suggested that ectopic Schwann cells could have been the origin of the tumors (1). Also, they suggested that schwannomas with a tight attachment to the dura may arise from Schwann cells ensheathing the small nerve twigs that innervate the dura. Other authors suggested that perivascular Schwann cells could have been the origin of the tumors $(8,9)$. In our case, the tumor was located anteriorly to the normal pituitary gland and stalk. Based on the operative findings, it seemed that the tumor developed in the area around dorsum sellae. Although the exact origin of the tumor in our case is still unclear, it is suggested that intrasellar schwannoma should be considered in the differential diagnosis of sellar lesions mimicking a pituitary adenoma.

\section{REFERENCES}

1. Russell DS, Rubinstein LJ. Pathology of the tumours of the nervous system, 5th ed. London: Edward Arnold 1989; 533-89.

2. Perone TP, Robinson B, Holmes SM. Intrasellar schwannoma: case report. Neurosurgery 1984; 14: 71-3.

3. Wilberger JE Jr. Primary intrasellar schwannoma: case report. Surg Neurol 1989; 32: 156-8.

4. Guenot M, Bataille B, Wager M. Intrasellar neurinoma. Apropos of a case and review of the literature. Neurochirurgie 1994; 40: 263-6.

5. Civit T, Pinelli C, Klein M, Auque J, Baylac F, Hepner H. Intrasellar schwannoma. Acta Neurochir 1997; 139: 160-1.

6. Johnsen DE, Woodruff WW, Allen IS, Cera PJ, Funkhouser GR, Coleman LL. MR imaging of the sellar and juxtasellar regions. 
Radiographics 1991; 11: 727-58.

7. Sobel RA, Michaud J. Microcytic meningioma of the falx cerebri with numerous palisading structures: an unusual histological pattern mimicking schwannoma. Acta Neuropathol 1985; 68: 256-8.
8. Gibson AA, Hendrick EB, Conen PE. Intracerebral schwannoma. Report of a case. J Neurosurg 1966; 24: 552-7.

9. New PF. Intracerebral schwannoma. Case report. J Neurosurg 1972; 36: 795-7. 